\title{
Provisional Outcomes of Affordable Custom Wheelchair Seating for an Individual with Cerebral Palsy: Case Report
}

\author{
Nattapong Polhan, Thanatat Charatrungolan*, Woratee Dacharux, \\ Juthamas Siriwatsopon, and Gary Guerra
}

Sirindhorn School of Prosthetics and Orthoics, Faculty of Medicine, Siriraj Hospital, Mahidol University, Bangkok, 10700 Thailand

*Corresponding author.E-mail: thanatat.cha@mahidol.edu

https://doi.org/10.12982/CMUJNS.2019.0021

\begin{abstract}
The person with cerebral palsy has a range of functional limitations which can restrict activities of daily living. Sitting for extended periods is a pertinent issue to address. Custom seating orthosis combined with a wheelchair could reduce issues associated with long-term sitting in this population. The custom seating system for a child with cerebral palsy GMFCS Level IV was provided and outcome measures which measured functional grasping and seat pressure distribution was evaluated while the patient was seated in a traditional wheelchair as well as the custom seating wheelchair.Time to complete tasks while seated in the custom seating wheelchair was longer in duration than when seated in the traditional wheelchair, however, pressure was reduced in pressure prone areas and distributed more across pressure tolerant areas. The custom seating system provided to this patient evidences the utility and usefulness of a customized orthotic intervention for the wheelchair intervention. Additional accommodation to the custom seating could posit differences in outcomes as would an increase in study participants.
\end{abstract}

Keywords: Orthosis, Cerebral palsy, Custom seating, Wheelchair, Assistive technology, Pressure distribution 


\section{INTRODUCTION}

The individual with cerebral palsy has a potentially wide range of functional limitations as a result of their condition (Beckung et al., 2008) The nature of this condition lends itself to a loss of an individual's ability to maintain postural control, and move and control muscles (CDC, 2014) Gross restriction of mobility for some of these individuals results in confinement to wheelchair. As such, this limited mobility can predicate long-term restrictions in joint movement, muscle atrophy, sensation disturbances and contractures of the lower extremities (Rosenbaum et al., 2007) Sitting in a fixed position with an inability to self-adjust posture and seating orientation is a cause for concern which can be a precursor for prolonged sitting pressures (Kim, Yoo and Do, 2017) The use of custom seating for these individuals has been shown to provide postural support through reduced trunk flexion and prevention of abnormal gluteal pressures (Yoo, 2015) We provide a case report on the function and seat pressures for an individual with cerebral palsy after prescription of an easily replicable custom seating system.

\section{Case description}

\section{MATERIALS AND METHODS}

A 22-year old man with tetraplegia spastic cerebral palsy and a Gross Motor Function Classification System (GMFCS) Level IV was evaluated for a wheelchair with customized seating.(Wood and Rosenbaum, 2000) An assessment by a physiatrist for manual muscle testing (MMT), Ashworth scale and Thomas Test (negative) were performed. In addition, flexible neuromuscular scoliosis with muscle tightness of $15^{\circ}$ on the right knee and $25^{\circ}$ on the left knee as well as pelvic obliquity was observed, see Table 1 . Sitting balance was determined to be within normal limits for both static and dynamic balance. The patient was sitting for approximately 8 hours a day in a standard manual wheelchair and had been using custom-made seating for two years prior. 
Table 1. Parameters of a 22-year-old male with cerebral palsy (GMFCS IV).

\section{Parameter}

\section{Height}

Weight

BMI

\section{Left}

\section{Right}

MMT

Deltoids

Biceps

4

4

Triceps

4

4

Digit flexion/extension

Wrist extensor

Hand function

Hip flexion/extension

Knee flexion/extension left

$2 / 4$

1

lateral pinch

1

$0 / 0$

NA

$0 / 0$

$0 / 1$

Upper extremity ROM

Shoulder flexion

130

150

Elbow extension

160

180

Wrist

Full

Full

$1^{\text {st }}$ web space

50

40

Supination

Full

45

Digit

Full

Full

Lower extremity ROM

$90 / 160$

90/160

Hip flexion/extension

Knee flexion/extension

Full/150

Full/150

Full

Full

Trunk-decompensation

Note: MMT: Manual Muscle Test; ROM: Range Of Motion. 


\section{Custom seating orthosis}

An orthotist created a custom-made seating orthosis which was prescribed by the physiatrist in order to provide a comfortable and optimal base of support for functional mobility. The participant was first seated in a vacuum bean bag apparatus (VBBA) at $10^{\circ}$ of posterior tilt, which enabled the acquisition of the individual contours and corrections of the rear and lower back of the patient (Figure 1).

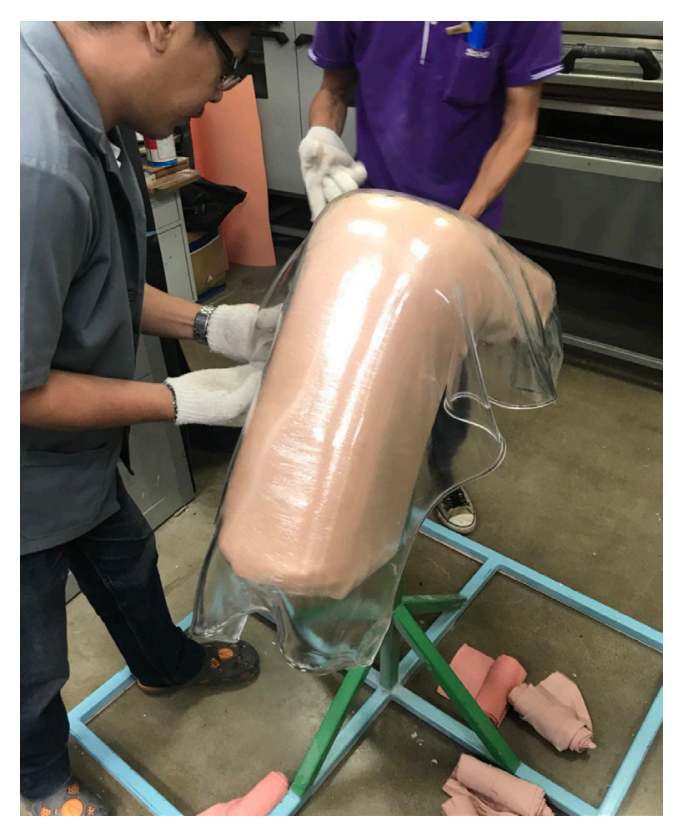

Figure 1. Image taken during fabrication of patients custom seating orthosis.

It is our anecdotal clinical experience that this orientation can reduce the asymmetrical hip flexion and posture which promotes a suitable weight bearing position.(Ágústsson, Sveinsson and Rodby-Bousquet, 2017) The participant was transferred out of the VBBA and a Plaster of Paris (POP) cast was made of the preserved custom seating of the VBBA. From the cast, a model was created, modified, and plastazote and polypropylene was then used and contoured to create the final wheelchair seat orthosis, see Figure 2. 

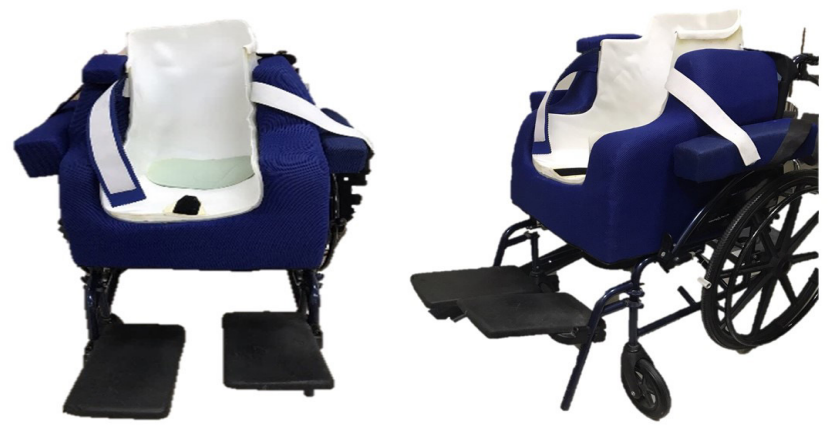

Figure 2. Image of the definitive custom seating orthosis wheelchair.

\section{Outcome measures}

The patient was seated in their wheelchair which was positioned directly in front of a testing table. Task objects were situated at the umbilicus level of the patient, $30 \mathrm{~cm}$ in front of the body. On this table were cylindrical objects of 2 and $5 \mathrm{~cm}$ in size. Task 1 (object transfer) required the patient to grab the object with their dominant hand and transfer to a designated location. Task 2 (cup to mouth) required the patient to use their dominant hand to pick up a small plastic cup and bring to their mouth. Task 3 (long distance cup reach) required the participant to reach to a longer distanced cup $60 \mathrm{~cm}$ in front of their body. A series of practice trials were permitted and finally three trials were performed and used for outcome data collection. During performance of these tasks an instrumented pressure distribution sensor (FSA, Vista Medical, Winnipeg, Canada) collected pressure metrics of the patient along the thighs, hip, and rear. Pressure distribution, peak pressures (Kpa), pressures at the ischial tuberosity, and average total pressures were all collected (Figure 3). We projected nine sections onto the detailed sensor output graphs for nine distinctive areas coinciding with nine postures of wheelchair users.(Verbunt and Bartneck, 2010)

\section{RESULTS}

The patient performed all three tasks for a longer duration of time while in the custom seating wheelchair as compared to the standard wheelchair, percent time increases were as follows; Task $1(54.9 \%)$, Task $2(8.9 \%)$, Task 3 $(5.8 \%)$. The visual results from the pressure mapping array evidenced increased localized pressure while the patient was in the standard wheelchair, up to the maximum set pressure of $200 \mathrm{mmHg}$ at the patients rear and ischial tuberosity which was evident across all outcome measurement tasks. In contrast, when the 
patient was seated in the custom seating wheelchair, pressures shifted from posterior to anterior sections along the interior of the middle thighs. Moreover, the patients pressure showed a wider distribution across this same section (Figure 3).

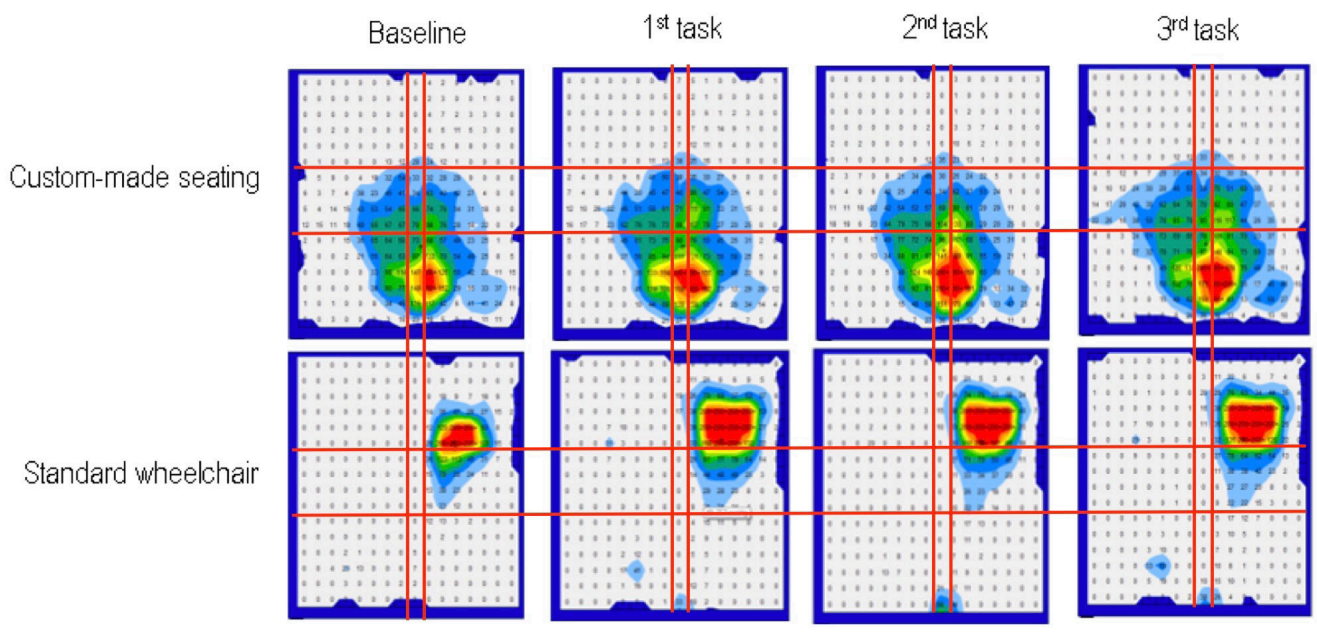

Figure 3. Pressure sensor pressure distribution mapping for the patient in the standard wheelchair (A), and custom seating wheelchair (B). Pressure readings from baseline and during three different tasks is illustrated. Patient pressure while seated in the standard wheelchair is centered around the ischial tuberosity as opposed to a more distributed pressure while seated in the custom seating wheelchair.

Table 2. Summary of all result.

\begin{tabular}{lcc}
\hline Tasks & Standard wheelchair & $\begin{array}{c}\text { Custom seating } \\
\text { wheelchair }\end{array}$ \\
\hline Task 1 $(\mathrm{sec})$ & 33.01 & 58 \\
Task 2 $(\mathrm{sec})$ & 15.8 & 17.28 \\
Task 3 $(\mathrm{sec})$ & 21.54 & 23.89 \\
Pressure location & Anterior and middle thighs & $\begin{array}{c}\text { Rear and ischial } \\
\text { tuberosity }\end{array}$ \\
Area of pressure distribution & Larger & Smaller \\
\hline
\end{tabular}




\section{DISCUSSION}

We evaluated the functional outcomes as well as pressure relieving capabilities of the wheelchair. Sitting in the custom seating orthosis wheelchair saw no decrease in the time taken to complete tasks, however, reduced pressures along the buttocks and an improved distribution of pressures were observed. Previous scholarship has evidenced the propensity for asymmetrical sitting postures in individuals with CP. (Lee and Park, 2015) In our case we were capable of reducing asymmetrical pressure which might have been related to a correction of the patient's posture. The greater time required for the patient to complete tasks might be related to the cognitive ability of the patient as we observed some inability of the patient to follow our guidance. Trunk control and the ensuing postural control is cornerstone to the functional abilities of the individual with CP. (Wu et al., 2004). Thus, the seat might play an integral role in dictating functional outcomes and should be investigated further.

\section{CONCLUSION}

A custom seating orthosis was developed to evaluate the force distribution occurred at the bottom during upper limb functions. The force was satisfied distribution with acceptable time spending compare with seating on a traditional wheelchair. However, the time spending on the custom seating orthosis was not significant improve which may cause from the severity of scoliosis and tilting angle of the orthosis effect trunk flexion motion result in a performance of upper limb function. On the other hand, traditional wheelchair allows some translation when the upper body perform some activities, but the excessive pressure remain present all the time. From these result, the further research can be focus on the relationship between the tilting angle and upper limb function during using a custom seating orthosis.

\section{ACKNOWLEDGEMENTS}

This project was mainly worked at Sirindhorn School of Prosthetics and Orthotics (SSPO School). 


\section{REFERENCES}

Ágústsson, A., Sveinsson, P., and Rodby-Bousquet, E. 2017. The effect of asymmetrical limited hip flexion on seating posture, scoliosis and windswept hip distortion. Research in Developmental Disabilities. 71: 18-23. https://doi.org/10.1016/j.ridd.2017.09.019

Beckung, E., Hagberg, G., Uldall, P., Cans, C., and for Surveillance of Cerebral Palsy in Europe. 2008. Probability of walking in children with cerebral palsy in Europe. Pediatrics. 121(1): e187-92. https://doi.org/10.1542/peds.20070068

CDC. 2014. Center for Disease Control and Prevention, Cerebral Palsy. Retrieved from http://www.cdc.gov/ncbddd/cp/facts.html.

Kim, D.H., Yoo, W.-G., and Do, J.-H. 2017. Changes in gluteal pressure and center of force during sitting in children with cerebral palsy. Journal of Physical Therapy Science. 29(12): 2210-2211. https://doi.org/10.1589/jpts.29.2210

Lee, I.-H., and Park, S.-Y. 2015. Abnormal sitting pressures of hemiplegic cerebral palsy children on a school chair. Journal of Physical Therapy Science. 27(2): 499-500. https://doi.org/10.1589/jpts.27.499

Rosenbaum, P., Paneth, N., Leviton, A., Goldstein, M., Bax, M., Damiano, D., Dan, B., and Jacobsson, B. 2007. A report: The definition and classification of cerebral palsy April 2006. Developmental Medicine and Child Neurology Supplement. 109: 8-14.

Verbunt, M., and Bartneck, C. 2010. Sensing senses: Tactile feedback for the prevention of decubitus ulcers. Applied Psychophysiology and Biofeedback. 35(3): 243-50. https://doi.org/10.1007/s10484-009-9124-z

Wood, E., and Rosenbaum, P. 2000. The gross motor function classification system for cerebral palsy: A study of reliability and stability over time. Developmental Medicine and Child Neurology. 42(5): 292-6.

Wu, Y.W., Day, S.M., Strauss, D.J., and Shavelle, R.M., 2004. Prognosis for ambulation in cerebral palsy: A population-based study. Pediatrics. 114(5): 1264-71. https://doi.org/10.1542/peds.2004-0114

Yoo, W.-G. 2015. Effect of a suspension seat support chair on the trunk flexion angle and gluteal pressure during computer work. Journal of Physical Therapy Science. 27(9): 2989-90. https://doi.org/10.1589/jpts.27.2989 